\title{
Venlafaxine induced akathisia: a case report
}

\author{
Acatisia induzida por venlafaxina: relato de um caso
}

\begin{abstract}
Venlafaxine - a serotonin, noradrenaline and dopamine reuptake inhibitor 1 - is a new generation antidepressant. The drug has been rarely reported to be associated with the development of akathisia. 2 A review of the literature in PubMed revealed only four cases reported to date. Different from previous cases in which patients developed akathisia at a dose of $150 \mathrm{mg} /$ day, we present the case of a 35-year-old male patient who developed akathisia with venlafaxine $75 \mathrm{mg} /$ day.

Our patient had been receiving psychiatric treatment for obsessive-compulsive disorder and avoidant personality disorder for the last 10 years. He was started on sertraline $50 \mathrm{mg} /$ day and shifted to venlafaxine 75 $\mathrm{mg} /$ day with cross-tapering. He was not on any other psychotropic or non-psychotropic drugs. Akathisia started on the third week of venlafaxine treatment. The patient could not fall asleep at night because of agitation: need to move his feet constantly, inability to sit for a long time, and need to rock his feet during daytime if he had to remain seated. As venlafaxine provided a marked improvement in compulsions, we continued the treatment and added propranolol $40 \mathrm{mg} /$ day for akathisia. Although propranolol relieved the patient's akathisia, symptoms did not disappear until we added clonazepam $1 \mathrm{mg} /$ day to the treatment as well. The patient complained about the sleepiness caused by clonazepam, so we withdrew this medication from the treatment. Even though he was taking propranolol, akathisia symptoms became more intense than before, leading us to gradually discontinue venlafaxine. Akathisia symptoms continued until 1 week after complete venlafaxine withdrawal. Meanwhile, compulsions significantly increased after venlafaxine discontinuation, and the patient was started on paroxetine $20 \mathrm{mg} /$ day, with no signs of akathisia. The patient's mother had a diagnosis of bipolar disorder for which she had used tricyclic antidepressants and
\end{abstract}

classical neuroleptic drugs for a long time, without any akathisia symptoms.

Four cases of venlafaxine induced akathisia have been reported in the literature. Three of those cases experienced akathisia at the dosage of $150 \mathrm{mg} / \mathrm{day}$, and one at $225 \mathrm{mg} /$ day. $^{2}$ In our case, the patient developed akathisia at the dosage of $75 \mathrm{mg} /$ day. Also, all the cases previously reported used other drugs and had comorbid diseases, ${ }^{2}$ whereas our patient did not have any comorbid disease and was not using any other medication that might lead to drug interactions. Finally, the patient's mother had taken psychotropic drugs for a long time, without any extrapyramidal side effects (EPS), which helped us rule out any genetic inheritance for EPS. Therefore, our conclusion is that even low doses of venlafaxine, such as $75 \mathrm{mg} /$ day, may cause akathisia.

\section{Mehmet Emin Ceylan, Alper Evrensel}

Üsküdar University, Istanbul, Turkey.

\section{References}

1. George M, Campbell JJ 3rd. Venlafaxine causing akathisia: a case report. J Neuropsychiatry Clin Neurosci. 2012;24:E3-4.

2. Grover S, Valaparla VL. Venlafaxine induced akathisia: a case report. Indian J Pharmacol. 2014;46:660-1.

\section{Correspondence:}

Alper Evrensel

Üsküdar University, Etiler Clinic, Nisbetiye Cad. No: 19, Besiktas Istanbul, Turkey

Tel.: +905057130182 - Fax: +902122701719

E-mail: alperevrensel@gmail.com

Submitted Dec 03 2015, accepted for publication Jan 042016. No conflicts of interest declared concerning the publication of this article.

Suggested citation: Ceylan ME, Evrensel A. Venlafaxine induced akathisia: a case report [letter]. Trends Psychiatry Psychother. 2016;38(2):117. http://dx.doi.org/10.1590/2237-6089-20150084 